\title{
Immunological Studies of Coagulation Factor XIII
}

\author{
E. D. Israeis, F. Paraskevas, and L. G. Israels \\ From the Departments of Pediatrics and Medicine, University of Manitoba and \\ the Clinical Investigation Unit of the Winnipeg Children's Hospital, \\ Winnipeg, Canada
}

A B S T R A C T Human fibrin-stabilizing factor (Factor XIII) has been studied immunologically by the preparation of specific anti-Factor XIII antiserum in rabbits. On immunodiffusion it was found that normal plasma produced two precipitin lines. One of the precipitin lines was identical with that present in soluble platelet extract (the $\alpha$-component), the other with that present in normal serum ( $\beta$-component). Plasma and serum of patients with congenital Factor XIII deficiency contained only the $\beta$-component. By adsorption it was possible to prepare a second antiserum with solely anti$\alpha$-activity that did not react with the serum or plasma of XIII-deficient patients. Both antisera neutralized the clot-stabilizing activity of normal plasma. The action of thrombin on fibrinogen-free plasma or platelet extract abolished the immunoprecipitin $\alpha$-line but did not reduce the capacity to neutralize antibody as measured by clot stabilization.

It is concluded that the plasma Factor XIII molecule consists of two immunologically identifiable components, $\alpha$ and $\beta$. The clot-stabilizing activity and thrombin-reactive site are situated on the $\alpha$-component. Patients with congenital Factor XIII deficiency are devoid of immunologically identifiable or functional $\alpha$-component but retain immunologically identifiable $\beta$-component. It is this $\beta$-component that accounts for the observed immunologically detectable Factor XIII in those patients devoid of clot-stabilizing activity.

\section{INTRODUCTION}

Factor XIII participates in the final step of blood coagulation by cross-linking of fibrin to form a stable clot. Clot-stabilizing activity has been demonstrated in normal plasma and in soluble platelet extracts but is absent from serum and from the plasma of patients with congenital Factor XIII deficiency. Using antiserum pre-

Received for publication 17 January 1973 and in revised form 11 April 1973. pared against isolated Factor XIII its presence, by immunological techniques, has been demonstrated in normal plasma (1) and platelet extracts (2), with approximately $50 \%$ levels in plasma of patients with congenital factor XIII deficiency ( 3 ).

The present study uses two antisera that neutralize Factor XIII activity but differ in their specificity. It was demonstrated that plasma Factor XIII consists of two immunologically identifiable components of which one is also present in platelets, the other in serum. The platelet-plasma component is altered by reaction with thrombin and is absent in patients with congenital Factor XIII deficiency whereas the plasma-serum component is not altered by thrombin and is present in the plasma of patients with congenital Factor XIII deficiency. It is this second component, which is unaltered by thrombin and has no clot-stabilizing activity, that accounts for the immunologically identifiable Factor XIII in patients with congenital Factor XIII deficiency.

\section{METHODS}

Preparation of plasma Factor XIII. The purification of plasma Factor XIII followed in part the method of Loewy, Dunathan, Kriel, and Wolfinger (4). However, fibrinogen was first adsorbed from the plasma with bentonite (5), thereby avoiding the usual procedure of heating to $56^{\circ} \mathrm{C}$. Neither clottable fibrinogen nor immunologically related protein was detected in the supernate, and this was confirmed by the absence of antibodies in the immunized rabbits capable of reacting with fibrinogen. It was necessary to adsorb the plasma soon after collection of the blood as the fibrinolytic products, which appear during storage, may not be removed completely by bentonite adsorption. Blood collected in acid citrate (6) was centrifuged at $10,000 \mathrm{rpm}$ for $10 \mathrm{~min}$, and the platelet-poor plasma was separated. Bentonite (Prolabo, Rhone-Poulenc, France), $23 \mathrm{mg} / \mathrm{ml}$, was added immediately to the plasma, stirred for $30 \mathrm{~min}$ at room temperature, and centrifuged, and the precipitate was discarded.

To prevent thrombin activation of Factor XIII during the purification procedure, prothrombin was removed by adsorption to aluminum hydroxide. 0.1 vol of aluminum hydroxide suspension (Amphojel, Wyeth Laboratories, 

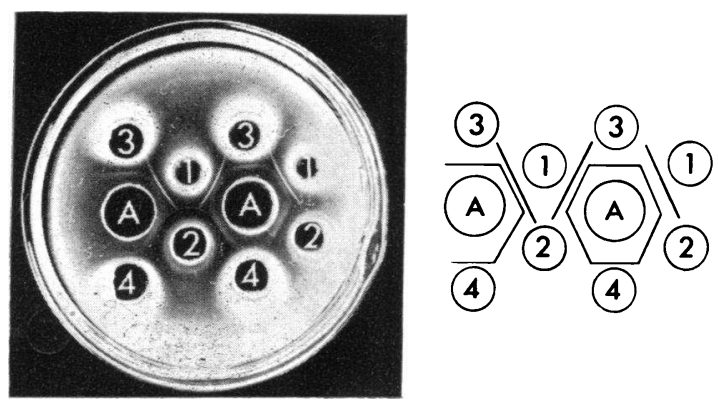

FIGURE 1 Immunodiffusion pattern with antiserum A against (1) normal plasma; (2) normal serum; (3) XIIIdeficient plasma; (4) XIII-deficient serum.

Philadelphia, $\mathrm{Pa}$.) was added to the supernate and after 10 min at room temperature was removed by centrifugation.

Ammonium sulfate ( $\mathrm{pH} 7)$, saturated at room temperature, was added to the supernate to a final concentration of $40 \%$ saturation, stirred for $2 \mathrm{~h}$ at $4^{\circ} \mathrm{C}$, and centrifuged. The precipitate, washed twice with a $40 \%$ saturated solution of ammonium sulfate, was redissolved in $0.15 \mathrm{M} \mathrm{KCl}$ in a volume equal to 0.1 of the original plasma volume. DEAE-cellulose chromatography was performed as described by Loewy et al. (4). Using stepwise elution, Factor XIII was eluted in the $0.2 \mathrm{M}$ phosphate buffer. This fraction was concentrated by pressure filtration and electrophorsed on $7.5 \%$ polyacrylamide gels (7). The protein bands in the gel were visualized and sectioned by the method of Hartman and Udenfriend using anilinonaphthalene sulfonate (8). The sections from one gel were eluted into saline and tested for Factor XIII activity. The Factor XIII-containing segments from the remaining gels were pooled, pulverized, and homogenized with an equal volume of complete Freund's adjuvant and injected subcutaneously into rabbits at 2 -wk intervals. Antiserum, harvested 4-6 wk later, neutralized the biological activity of Factor XIII of normal plasma. This XIII-neutralizing capacity of the antiserum was not detectably diminished by incubation of the antiserum with plasma from either of two Factor XIIIdeficient patients.

Platelet Factor XIII. Soluble platelet extract containing Factor XIII activity was prepared by the method of McDonagh, McDonagh, Delage, and Wagner (9).
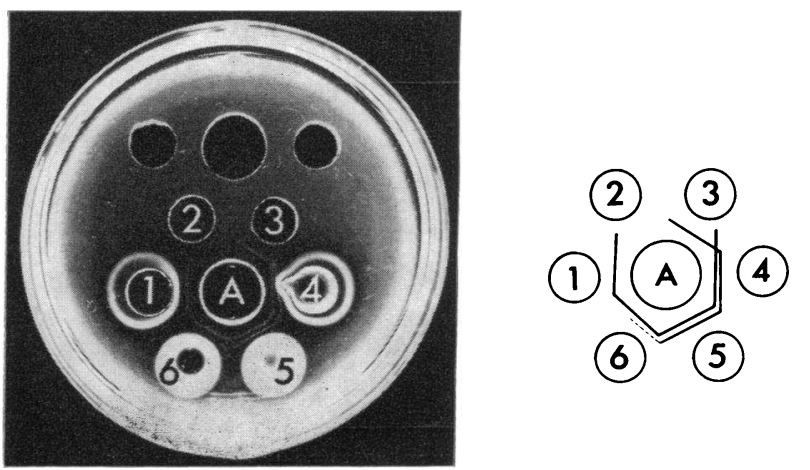

FIGURE 2 Immunodiffusion pattern with antiserum A against (1) normal serum; (2) platelet extract treated with thrombin; (3) platelet extract; (4) normal plasma; (5) bentonite-adsorbed normal plasma; (6) bentonite-adsorbed normal plasma treated with thrombin.
Fibrinogen-frec plasma. Normal plasma was adsorbed with bentonite, $23 \mathrm{mg} / \mathrm{ml}$, at room temperature for $30 \mathrm{~min}$ stirring gently. The precipitate was separated by centrifugation and discarded.

Preparation of specific antiscra. Antibodies reacting with serum proteins other than Factor XIII were removed from the rabbit immune serum by adsorption onto water-insoluble protein polymers prepared with ethyl chloroformate (10) from the serum of a patient with congenital Factor XIII deficiency. This preparation, which on immunodiffusion gave two precipitin lines with normal plasma and one with normal serum, is designated antiserum A. That it was possible to remove antibodies unrelated to Factor XIII with this technique without substantially decreasing its apparent immunological reactivity with the plasma and serum of XIII-deficient patients may be explained in two ways: (a) Not all serum proteins are completely incorporated during the formation of the water-insoluble polymers and it may be that little or none of the Factor XIII protein was present in the complex. (b) The small amount of Factor XIII or XIII-like material in the serum of XIII-deficient patients. On immunodiffusion the precipitin line that developed against XIII-deficient serum was weaker and closer to the antigen well than that of normal serum. A semiquantitation of the Factor. XIII-antigen in serum was obtained by immunodiffusion using serial dilutions. A precipitin line with normal serum was visible to a dilution of one in four, whereas only undiluted XIII-deficient serum gave a precipitin line. That this precipitin line is much weaker in XIII-deficient serum as compared with the plasma of the same patient suggests that some of this component of the Factor XIII protein was adsorbed to and removed with the fibrin clot. The fact that the apparent concentration of this antigenic determinant in normal serum does not appear diminished in comparison to normal plasma may be explained by the fact that the double diffusion technique is not a sensitive quantitative assay and does not reflect changes in protein concentration, except when these approach the threshold of this technique.

Antiserum A on double diffusion developed precipitin lines with plasma and serum from both normal and Factor XIIIdeficient patients (Fig. 1). Two precipitin lines were present with normal plasma. One line showed complete identity with the single precipitin line exhibited by normal serum, and the serum and plasma from XIII-deficient patients. The other line of normal plasma showed identity only with that of soluble platelet extract (Fig. 2).

Antiserum A was further adsorbed with small portions of Factor XIII-deficient plasma until only one precipitin line with normal plasma was present. This preparation, which gave only a single line with normal plasma, was designated antiserum B. Antiserum $B$ did not develop precipitin lines with normal serum nor with the plasma or serum from XIII-deficient patients (Fig. 3). It did yield one precipitin line with both normal plasma and with platelet extract and retained its capacity to neutralize the fibrinstabilizing activity of normal plasma.

Antibody neutralization tests. The test material was first incubated with anti-Factor XIII (either antiserum A or B). Normal plasma was added, and the mixture was incubated for an additional period to allow any unbound antibody to neutralize the Factor XIII of the normal plasma. Serial dilutions were prepared and assayed for clot-stabilizing activity. The proportions of the reactants in the test system were chosen to give an end point between $1 / 8$ and 1/256. $0.1 \mathrm{ml}$ antiserum was incubated with $0.1 \mathrm{ml}$ test material 
at $37^{\circ} \mathrm{C}$ for $30 \mathrm{~min}, 0.2 \mathrm{ml}$ normal plasma was added, and the mixture was incubated for an additional $30 \mathrm{~min}$ at $37^{\circ} \mathrm{C}$. Serial dilutions of this mixture were prepared in saline (from $1 / 2$ to $1 / 1,024$ ) so that each tube contained a volume of $0.2 \mathrm{ml} .0 .2 \mathrm{ml}$ Factor XIII-deficient plasma (as a source of XIII-free fibrinogen) followed by $0.4 \mathrm{ml}$ $\mathrm{CaCl}_{2}(0.025 \mathrm{M})$ and $10 \mathrm{U}$ of thrombin was added to each tube. The clots, which formed immediately, were left at $37^{\circ} \mathrm{C}$ for $1 \mathrm{~h}$. Then $6 \mathrm{ml}$ of $5 \mathrm{M}$ urea was added to each tube and left at room temperature for $18 \mathrm{~h}$. The last tube containing a visible clot was read as the titer.

\section{RESULTS}

Double diffusion in agar. Antiserum A formed two precipitin lines with normal plasma and with fibrinogenfree bentonite-adsorbed plasma (Fig. 2). These two precipitin lines and the Factor XIII component they represent will be referred to as $\alpha$ and $\beta$. The first precipitin line, $\alpha$-line, (closest to the antigen wells) showed complete identity with the single precipitin line formed with Factor XIII derived from platelets. The second precipitin line, closest to the antibody well, ( $\beta$-line), present in normal and bentonite-adsorbed plasma showed identity with the line formed by serum and the single line formed by the plasma of Factor XIII-deficient patients. After treatment with thrombin, platelet Factor XIII no longer formed a precipitin line on double diffusion, and the bentonite-adsorbed plasma treated with thrombin now developed only a single $\beta$-precipitin line, although sometimes a weak $\alpha$-line remained.

The antiserum that had been adsorbed with XIIIdeficient plasma (antiserum B) formed only a single line with normal plasma, with bentonite-adsorbed plasma, and with platelet extract (Fig. 3). There was no precipitin line against normal serum nor against plasma
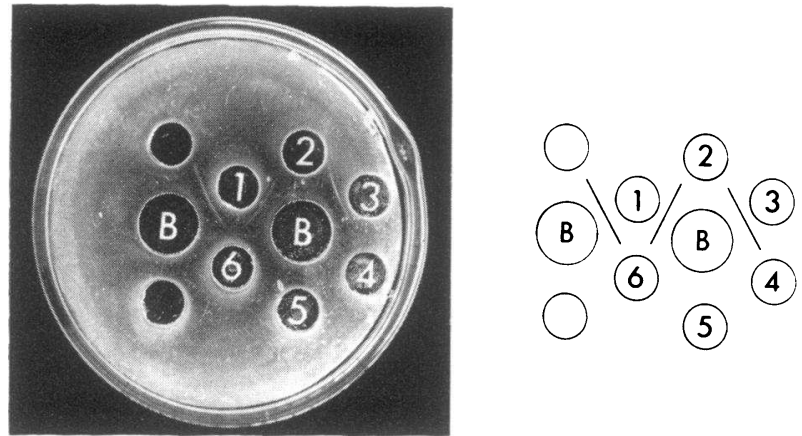

FICCRE 3 Immunodiffusion pattern with antiserum B against (1) normal plasma; (2) normal serum; (3) bentonite-adsorbed normal plasma; (4) bentonite-adsorbed normal plasma treated with thrombin; (5) XIII-deficient plasma; (6) XIII-deficient serum.

or serum of Factor XIII-deficient patients. The precipitin line was either very faint or completely absent when bentonite-adsorbed plasma or soluble platelet extract had been treated with thrombin.

Antibody neutralization tests. The results using antiserum $A$ are shown in Table I. Those with antiserum B are identical. Normal plasma, bentonite-adsorbed plasma, and platelet extract neutralized both antisera. This is seen in the test system, as there was no inhibition of the Factor XIII present in the added normal plasma. The titers in these experiments are therefore high reflecting the XIII level of the normal plasma added at step 2. When bentonite-adsorbed plasma or platelet extracts were pretreated with thrombin, their neutralizing capacity remained unchanged. In contrast, saline, normal serum, and XIII-deficient plasma and serum did not

TABLE I

Antibody-Neutralization Test

\begin{tabular}{clc}
\hline Experiment & \multicolumn{1}{c}{ Incubation of antiserum A with: } & $\begin{array}{c}\text { Titer } \\
\text { (highest dilution } \\
\text { with stable clot) }\end{array}$ \\
\hline 1 & Saline & $1 / 8$ \\
2 & Serum & $1 / 8$ \\
3 & Plasma & $1 / 256$ \\
4 & Bentonite-adsorbed plasma & $1 / 256$ \\
5 & Bentonite-adsorbed plasma treated with thrombin & $1 / 256$ \\
6 & Platelet extract & $1 / 128$ \\
7 & Platelet extract treated with thrombin & $1 / 128$ \\
8 & XIII-deficient plasma (D. C.) & $1 / 8$ \\
9 & XIII-deficient plasma (H. Z.) & $1 / 8$ \\
\hline
\end{tabular}

After a $30 \mathrm{~min}$ incubation of the antiserum with the test material, normal plasma is added and incubated for an additional $30 \mathrm{~min}$. During this latter period any residual antibody will neutralize the Factor XIII in the added plasma. The amount of unneutralized Factor XIII is assayed for clot-stabilizing activity and quantitated by serial dilution. The titers represent the highest dilution capable of stabilizing a fibrin clot prepared from XIII-deficient plasma. (See text for method.) 
neutralize the antiserum, which was then free to react with the normal plasma added at step 2. These titers are therefore low reflecting the neutralization of the added plasma Factor XIII by the free antibody. Thus all those substances capable of neutralizing antibody activity, as measured by its interference with clot stabilization, contained the $\alpha$-component. Those containing only the $\beta$-component were unable to neutralize the antibody. This would indicate that the clot-stabilizing activity of the Factor XIII molecule resides in the $\alpha$-component.

Identification of the $\beta$-precipitin line as part of the Factor XIII moleculc. As clot-stabilizing activity was identified only with the $\alpha$-precipitin line and not with the $\beta$-line it was necessary to demonstrate that the $\beta$-line was part of, or associated with the Factor XIII molecule. This was done by demonstrating that antiserum to the $\alpha$-component (antiserum B) also removed the $\beta$-component from normal plasma.

Insoluble complexes of antiserum B (anti- $\alpha$ )-Sepharose were prepared as follows. The gamma globulin fraction from $5 \mathrm{ml}$ of antiserum $\mathrm{B}$ was precipitated at $30 \%$ ammonium sulfate saturation $\left(\mathrm{pH} 7,25^{\circ} \mathrm{C}\right)$. The precipitate, washed twice with $30 \%$ saturated ammonium sulfate was resuspended in $3 \mathrm{ml}$ buffer $(0.1 \mathrm{M}$ $\mathrm{NaHCO}_{3}, 0.5 \mathrm{M} \mathrm{NaCl} \mathrm{pH} \mathrm{8}$ ) and dialyzed overnight against the same buffer. Immunodiffusion of this gamma globulin preparation against normal plasma and serum showed the identical pattern as the original antiserum. The gamma globulin was then coupled to $1 \mathrm{~g} \mathrm{CNBr}$ activated Sepharose 4B (Pharmacia Fine Chemicals Inc., Piscataway, N. J.) using the method described by the manufacturer and a column $(1.2 \mathrm{~cm}$ ID) was prepared. Normal plasma ( $2 \mathrm{ml}$ ) was applied to the column and eluted with $0.01 \mathrm{M}$ potassium phosphate-buffered saline $\mathrm{pH}$ 7.4. The eluate was collected in $0.5-\mathrm{ml}$ aliquots and the fractions examined by immunodiffusion against antiserum A. Finally the aliquots were pooled and concentrated by dialysis against polyvinylpyrrolidinone ( $45 \%$ solution, $160,000 \mathrm{~mol} \mathrm{wt}$ ) to a final volume of $1 \mathrm{ml}$ and examined by immunodiffusion and for clotstabilizing activity. The plasma eluted from the column on immunodiffusion showed no precipitin lines against antiserum $\mathrm{A}$ (anti- $\alpha$ and anti- $\beta$ ) and lacked clot-stabilizing activity indicating that the Sepharose-antiserum B (anti- $\alpha$ ) was able to remove both the $\alpha$ - and $\beta$-components from normal plasma. Normal rabbit gamma globulin coupled to activated Sepharose did not remove immunological or biological Factor XIII activity from normal plasma.

\section{DISCUSSION}

These immunological studies of human fibrin-stabilizing factor provide further information as to the two-compo- nent structure of the molecule and the identification of the biologically active site on only one of these components. Clot-stabilizing activity and antibody neutralization capacity is a function of normal plasma, fibrinogenfree bentonite-adsorbed plasma and soluble platelet extract. These all share the immunologically identical $\alpha$-line (as defined in Results). That this component is associated with the biological activity of the molecule is further suggested by the disappearance of this line from all three antigens after thrombin activation. The $\beta$-line is common to normal serum and to plasma and serum from patients with Factor XIII deficiency, and is not associated with the capacity to stabilize the clot. Thus, it is devoid of measurable Factor XIII activity and probably is associated with a part of the molecule distinct from the active biological site.

Loewy et al. (4) demonstrated that plasma Factor XIII consisted of two subunits. This was confirmed by Bohn (1) and by Bohn, Haupt, and Kranz (11) who showed that Factor XIII separated from platelets and from placenta contained only a single component that resembled one of the plasma subunits. The understanding of the structure of Factor XIII was further extended by the studies of Schwartz, Pizzo, Hill, and McKee (12) who showed that plasma Factor XIII consists of two polypeptide chains they designated $a$ and $b$. Platelet Factor XIII had only one type of polypeptide chain which appeared to be identical with the $a$-chain of plasma Factor XIII. After the action of thrombin the molecular weight of the $a$-chain decreased whereas the $b$-chain remained unchanged. They concluded that the active fibrin-stabilizing site was associated with the $a$-chain. Takagi and Konishi (13) and Bohn et al. (11) reported similar findings.

The present results may be interpreted in the light of these biochemical studies. Antiserum A which develops two precipitin lines with normal plasma consists of two antibody species, one reacting with normal plasma and soluble platelet extract, the other with a factor common to normal serum and plasma and XIIIdeficient serum and plasma. Since only the $a$-chain was demonstrated in platelet Factor XIII, (12), we will refer to the antibody that reacts with platelet extract as anti- $\alpha$-chain, and the antibody that reacts with serum and XIII-deficient plasma will be referred to as anti- $\beta$ chain. Antiserum A then contains both anti- $\alpha$-chain and anti- $\boldsymbol{\beta}$-chain antibodies. Antiserum B, which on immunodiffusion reacts only with normal plasma and platelet extract, is then specifically anti- $\alpha$-chain. In the antibody neutralization test, identical results were obtained using either antiserum $\mathrm{A}$ or antiserum $\mathrm{B}$. The antibody neutralization test then is specifically a measure of the presence of $\alpha$-chain and is uninfluenced by the presence of $\beta$-chain in the test material or by anti- 
$\beta$-chain antibody. The ability of normal plasma and platelet extract to neutralize these antisera in the test system is a measure of their $\alpha$-chain content and correlates with their ability to stabilize the fibrin clot. The absence of $\alpha$-chain in normal serum and in XIII-deficient serum and plasma is associated with the lack of fibrin-stabilizing activity. Thus $\alpha$-chain alone correlates with biological clot-stabilizing activity.

This raises the question as to whether the $\beta$-precipitin line is part of the molecule or complex possessing Factor XIII activity. This was established by the finding that antiserum B (anti- $\alpha$ )-Sepharose was able to remove both the $\alpha_{-}$and $\beta$-components from normal plasma. That immunodiffusion of antiserum $A$ and normal plasma produces two precipitin lines suggests that the two components of Factor XIII are held together noncovalently since they separate on diffusion in agar. It is also of interest that in the double diffusion system using antiserum $\mathrm{A}$ the concentration of the $\beta$-component is less in deficient serum than in normal serum.

Bohn (1) using antiserum prepared against plasma Factor XIII, demonstrated two precipitin lines with purified plasma Factor XIII on double diffusion, but could demonstrate only a single line with normal plasma. One of these lines showed complete identity with the precipitin line formed with purified platelet Factor XIII, the second precipitin line showed complete identity with that line developed against normal serum. A fraction designated by Bohn as "split product" derived from plasma Factor XIII by heat or by thrombin treatment showed complete identity with the line of normal serum. Antiserum prepared against this split product did not inhibit the fibrin-stabilizing activity of normal plasma in contrast to the antiserum prepared against plasma Factor XIII. The antiserum prepared by Kiesselbach and Wagner (2) contained a single antibody species that gave one precipitin line with plasma and soluble platelet extract and no reaction with serum.

Bohn (1) found that plasma of patients with congenital Factor XIII deficiency reacted only with his "antisplit" product antiserum. The "A subunit" of Bohn, which was present in normal plasma, platelets, and placenta, was absent in these patients. In congenitally deficient patients using our antiserum $A$ the precipitin line of the $\alpha$-chain is missing, and only $\beta$-chain is demonstrable. This $\beta$-chain is immunologically identical with that found in normal serum. It therefore would appear that these patients have an intact $\beta$-chain that may be quantitatively reduced (vide supra). That the plasma of these patients fails to neutralize the antiserum in the antibody neutralization test is also evidence that either $\alpha$-chain is absent or is so altered as to be immunologically nonreactive. McDonagh et al. (9) by polyacryla- mide disc electrophoresis of the platelet extract, demonstrated Factor XIII activity in a single protein peak. This peak was absent in Factor XIII-deficient platelet extract, suggesting that the $\alpha$-chain is in fact missing from the platelets of these patients.

Using radial immunodiffusion it has been demonstrated that plasma from patients with Factor XIII deficiency had immunologically identifiable Factor XIII that approximated $50 \%$ of normal $(3,14,15)$. This would be consistent with the use of an antiserum with both anti$\alpha$-chain and anti- $\beta$-chain activity. An exchange of serum with Dr. F. Duckert of Basel showed that Factor XIII-deficient patients with no immunological identifiable material to our antiserum B (adsorbed) were reactive in his system. Using the radial diffusion technique, the $50 \%$ of normal reactivity found in the plasma of these patients probably represents the presence of $\beta$-chain.

The immunodiffusion pattern of platelet extract and bentonite-adsorbed plasma is altered when these preparations are treated with thrombin in that no precipitin line forms with platelet extract and only the $\beta$-line remains in the bentonite-adsorbed plasma. That is, the $\alpha$-line disappears. This may be explained by the findings of Schwartz et al. (12) who demonstrated that the molecular weight of the $\alpha$-chain decreased after exposure to thrombin. However, both the platelet extract and the bentonite-adsorbed plasma when treated with thrombin retain their capacity to neutralize the antiserum in the antibody neutralization test. That is, they are still capable of binding anti- $\alpha$-chain. After the action of thrombin the altered $\alpha$-chain apparently cannot form the extensive lattices with the antibody necessary for precipitation, but is still capable of binding and neutralizing anti- $\alpha$-chain antibody. It is interesting that the transamidase isolated by Harding and Rogers (16) from guinea pig hair follicles reacts similarly with rabbit antihuman Factor XIII. This transamidase, which does not require activation by thrombin, did not form a precipitate with the antihuman Factor XIII, although it was inactivated by the antibody (16).

The fact that normal serum contains only $\beta$-chain and does not neutralize the antisera as does the thrombintreated bentonite-adsorbed (fibrinogen-free) plasma may be related to the removal of altered $\alpha$-chain on the fibrin clot. It is probable that after thrombin action and fibrin formation there is a splitting of the plasma Factor XIII molecule into its peptide chains with loss of all the altered $\alpha$-chain to the fibrin clot. Some of the $\beta$-chain may also be lost in the clot. The role of $\beta$-chain is unclear, both Schwartz et al. (12) and Bohn et al. (11) suggest that it may function in the stabilization of the plasma zymogen. 


\section{ACKNOWLEDGMENTS}

We are indebted to Dr. F. Duckert for the exchange of sera and for expert technical assistance to Mrs. Joan Swaffer and Miss Lorraine Bangard.

This work was supported by a grant from the Manitoba Heart Foundation.

\section{REFERENCES}

1. Bohn, H. 1971. Immunochemical studies on the fibrin stabilizing factors from human plasma and platelets. Blut Z. Gesamte Blutforsch. 22: 237.

2. Kiesselbach, T. H., and R. H. Wagner. 1966. Fibrinstabilizing factor: a thrombin-labile platelet protein. Am. J. Physiol. 211: 1472.

3. Becker, W., F. W. Gierhake, and H. G. Schwick. 1969 Die immunologische bestimmung des Faktor XIII Thromb. Diath. Hacmorrh. 34(Suppl.) : 15.

4. Loewy, A. G., K. Dunathan, R. Kriel, and H. L. Wolfinger, Jr. 1961. Fibrinase. I. Purification of substrate and enzyme. J. Biol. Chem. 236: 2625.

5. Josso, F., E. Palmstrom, J. Rewin, and M. Steinbuch 1964. Solution de proteines stabilisees obtenue après traitement du plasma humain par la bentonite. Preparation and properties. Proc. Congr. Int. Soc. Blood Transfus. 9: 142.

6. Proctor, R. R., and S. I. Rapaport. 1961. The partial thromboplastin time with kaolin. An. J. Clin. Pathol. $36: 212$.

7. Davis, B. J. 1964. Disc electrophoresis. II. Method and application to human serum proteins. Ann. N.Y. Acad. Sci. 121: 404.
8. Hartman, B. K., and S. Udenfriend. 1969. A method for immediate visualization of proteins in acrylamide gels and its use for preparation of antibodies to enzymes. Anal. Biochem. 30: 391.

9. McDonagh, J., R. P. McDonagh, Jr., J. M. Delage, and R. H. Wagner. 1969. Factor XIII in human plasma and platelets. J. Clin. Invest. 48: 940.

10. Avrameas, S., and T. Ternynck. 1967. Biologically active water-insoluble protein polymers. I. Their use for isolation of antigens and antibodies. J. Biol. Chem. 242: 1651.

11. Bohn, H., H. Haupt, and T. Kranz. 1972. Die molekulare struktur der fibrinstabilisierenden faktoren des menschen. Blut. Z. Gesamte Blutforsch. 25: 235.

12. Schwartz, M. L., S. V. Pizzo, R. L. Hill, and P. A. McKee. 1971. The subunit structures of human plasma and platelet factor XIII (fibrin-stabilizing factor). $J$. Biol. Chem. 246: 5851 .

13. Takagi, T., and K. Konishi. 1972. Purification and some properties of fibrin stabilizing factor. Biochim. Biophys. Acta. 271: 363 .

14. Egbring, R., K. Andrassy, H. Egli, and J. MeyerLindenberg. 1970. Untersuchungen bei zwei patienten mit kongenitalem Faktor-XIII-Mangel. Thromb. Diath. Haemorrh. 23: 313.

15. Duckert, F. 1970. Hereditärer mangel an Faktor XIIIaktivität synthese eines funktionslosen proteins. Schweiz. Med. Wochenschr. 100: 328

16. Harding, H. W. J., and G. E. Rogers. 1972. Formation of the $\epsilon$ - $(\gamma$-glutamyl $)$ lysine cross-link in hair proteins. Investigation of transamidases in hair follicles. Biochcmistry. $11: 2858$. 